\title{
New Ion Selective Sensitive Electrode of Pd (II) as Multisensor Based on IRA-410 via Low Cost Oxidation Reduction Process
}

\author{
AT Kassem*, N El Said, and HF Aly \\ Hot Labs. Center, Atomic Energy Authority, P.C. 13759, Cairo, Egypt
}

\begin{abstract}
A novel ion selective IRA-410 membrane disc sensor for $\mathrm{Pd}$ (II) ions has been prepared and studied. This electrode has a wide linear dynamic range from $10^{-1}$ to $2.5 \times 10^{-6} \mathrm{~mol}^{-1}$ with a Nernstian slope of $16.5 \pm 0.2 \mathrm{mV}$ decade ${ }^{-1}$ and low detection limit of $1.6 \times 10^{-6} \mathrm{~mol} \mathrm{I}^{-1}$. It has a fast response time $(<1 \mathrm{~s})$ and good selectivity with respect to different metal ions. IRA-410 based electrode was suitable for aqueous solutions of $\mathrm{pH}$ range from (1.0-9.0). It can be used for about 10 months with complex with Pd (II) was calculated by using segmented sandwich membrane method. The formation constant of ionophore of IRA-410 and its Pd (II)-Complex is examined using Fourier-transform infrared analysis and elemental analysis techniques. The proposed electrode has been used successfully as an indicator electrode in potentiometric determination in aqueous nitrate and /or chloride media.
\end{abstract}

Keywords: Membrane sensor; Nernstian slope; IRA-410 based electrode; Ionophore complex; Aqueous and nitrate media.

\section{Introduction}

Separation of palladium by strongly basic anion exchangers IRA-410 and IRA-900 from intermediate radioactive liquid waste in chloroacetic acid/nitrate medium containing thirteen elements have been achieved. Different conditions have been studied, the effect of $\mathrm{NaNO}_{3}$ as salt content, chloroacetic acid and hydrogen ion concentration have been investigated. Selective recovery of palladium from the [ILLW] solution was achieved using the column technique. The selectivity increased by using chloroacetic acid/nitrate than in nitrate medium. The elution of palladium was carried out via reduction with formic acid [1-3] where the rate of the reduction process was increased by decreasing

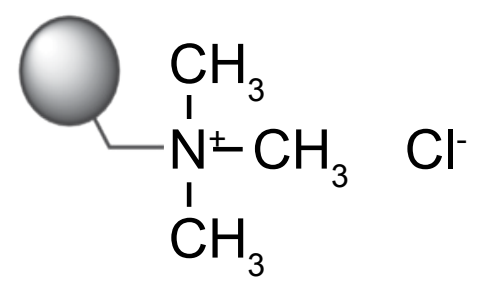

Figure 1: Structure: Amberlite IRA- 410 in chloride medium.

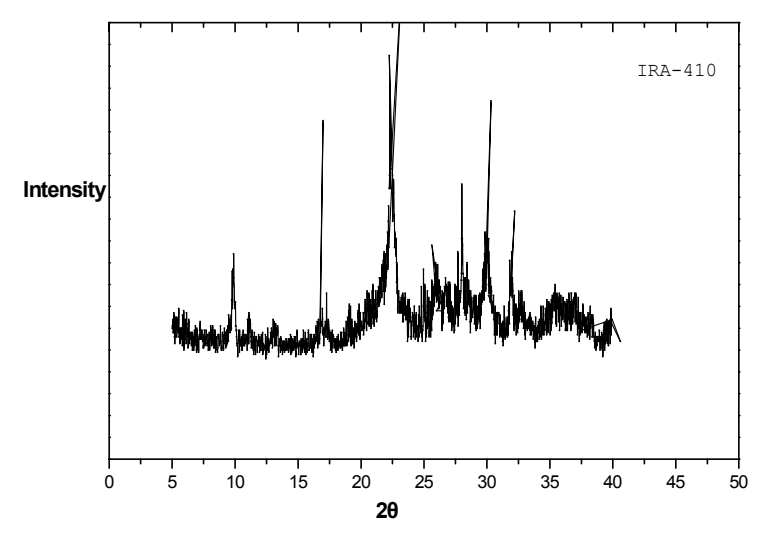

Figure 2: XRD Pattern for PVC on pd after. the formic acid concentration till $50 \%$ followed by dissolving the separated palladium by nitric acid. Selective efficient method is used for separation of palladium [4-12] by strongly basic anion exchangers IRA-410 and IRA-900 from intermediate radioactive nitrate medium different conditions for exchange behaviour of palladium from (ILLYO solutions containing number of elements were investigated by batch technique. Selective recovery of palladium from (ILLW) solution was achieved using column technique the elution [13] of palladium was carried out via reduction with formic acid. Ion-selective electrode based potentiometry has become a well-established electro-analytical technique. In this technique the most exciting and fastest growing area of research is the use of ion sensitive membrane electrodes for analysis of wastewater containing heavy metals. Using this approach the applicability of the potentiometric method has been greatly extended [14-17] enabling the simple and accurate determinations of many heavy metal ions and has led to a search for suitable materials that can be used for preparation of sensitive and selective ion-sensors, chemical sensors or more commonly ion-selective electrodes ((ISEs) $[18,19]$. Ion selective electrode based on palladium (II) dichloride acetylthiophene fenchone azine (I) has been developed.

\section{Experiment}

\section{Reagents and chemicals}

The strongly basic anion exchanger was used as previously described [4]. The plasticizers were obtained from Aldrich (Milwaukee, WI). While poly vinyl chloride powder (PVC) were obtained from Fluka (Buchs, Switzerland). The chloride salts of all cations studied (Figure 1).

\section{XRD and SEM characterization of Amberlite-410}

As it is shown in Figures 2, 3a and 3b, Pd (II) was chosen as the

*Corresponding author: AT Kassem, Hot Labs. Center, Atomic Energy Authority, P.C. 13759, Cairo, Egypt, Tel: 2020106369977 ; E-mail: nessemsalam@gmail.com Received February 05, 2014; Accepted February 18, 2014; Published February 25,2014

Citation: Kassem AT, El Said N, Aly HF (2014) New lon Selective Sensitive Electrode of Pd (II) as Multisensor Based on IRA-410 via Low Cost Oxidation Reduction Process. J Membra Sci Technol 4: 127. doi:10.4172/2155-9589.1000127

Copyright: (c 2014 Kassem AT, et al. This is an open-access article distributed under the terms of the Creative Commons Attribution License, which permits unrestricted use, distribution, and reproduction in any medium, provided the original author and source are credited. 


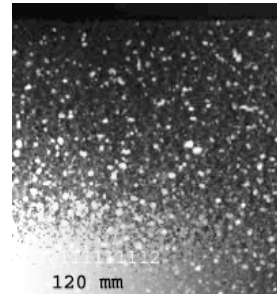

3a

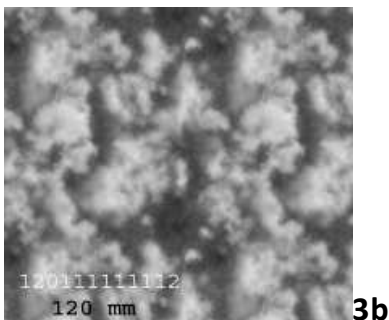

Figure 3: The SEM for PVC and Pd(II) (before)

\begin{tabular}{|c|c|c|c|c|}
\hline Resin & C\% & N\% & O\% & Cl\% \\
\hline IRA-410 & 85 & 12 & 2.33 & 0.67 \\
\hline
\end{tabular}

Table 1: Elemental analysis results after addition the IRA-410

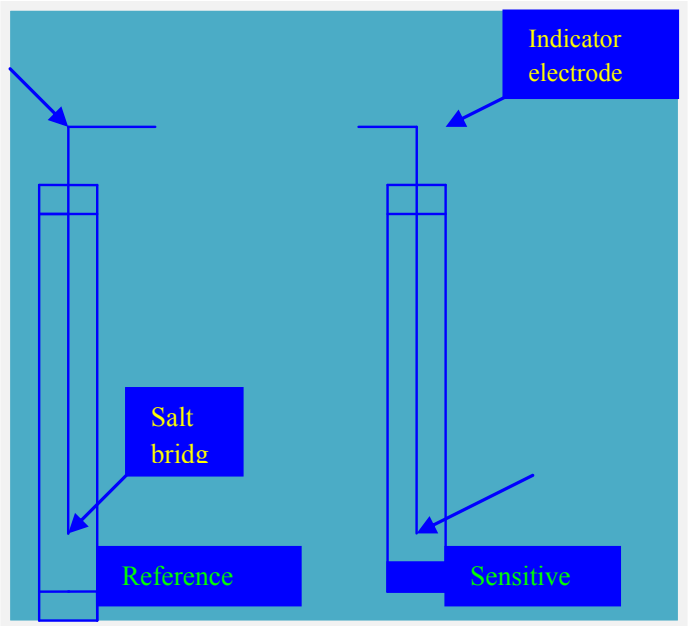

Figure 4: Experimental set- up for potentiometry.

\begin{tabular}{|c|c|c|c|c|c|}
\hline Membrane & PVC & $\begin{array}{l}\text { Composition \% } \\
\text { Plasticizer }\end{array}$ & NBPP & Additive & $\begin{array}{l}\text { Slope } / m V \\
\text { decade }^{-1} \text { ) }\end{array}$ \\
\hline 1 & 60 & 2,NaTFPB & -------- & $2, K T C I P B$ & $12.5 \pm 0.2 \mathrm{mV}$ \\
\hline 2 & 60 & $2, N a T F P B$ & -------- & $2, K T C I P B$ & $28.4 \pm 0.2 \mathrm{mV}$ \\
\hline 3 & 60 & $2, N a T F P B$ & 0.8 & $4, K T C I P B$ & $14.6 \pm 0.2 \mathrm{mV}$ \\
\hline 4 & 60 & $4, N a T F P B$ & 1.2 & $4, K T C I P B$ & $9.8 \pm 0.2 \mathrm{mV}$ \\
\hline 5 & 60 & 2,NaTFPB & 1.6 & $3, K T C I P B$ & $12.4 \pm 0.2 \mathrm{mV}$ \\
\hline
\end{tabular}

Table 2: Optimization of membrane ingredients.

appropriate sorbent for the sorption of Amberlite-410 among all the sorbents tested in this work. X-ray powder diffraction (XRD) characterization showed that the natural samples of Amberlite-410, Figure 2: XRD pattern of acid-treated. Amberlite- 410 with $2 \mathrm{MHCl}$ almost pure. Elemental content of the mineral was revealed using energy dispersive X-ray spectroscopy (EAR). The percentages of the elements are given in Table 1 . The values given correspond to an average of Data points selected randomly on the surface of Amberlite-410. A scanning electron microscope (SEM) micro image is provided in Figures 2, 3a and $3 b$. This Figures show typical Amberlite-410 crystals with sizes varying up to several $\mu \mathrm{m}$.

Powder XRD pattern of Pd nanoparticles is shown in Figure 2. The $\mathrm{d}$-spacing corresponding to XRD lines is $2.236, \mathrm{~A}^{\circ}$. These $\mathrm{d}$-spacing values correspond to (111), (planes with lattice constant, $a=3.871$ $\mathrm{A}^{\circ}$. This observation confirms the presence of metallic Pd with fcc structure. XRD line corresponding to $\{111\}$ plane is found to be unusually intense. SEM images of black particles are shown in Figure $3 \mathrm{a}$ and $3 \mathrm{~b}$. Aggregates of irregular-shaped particles are observed and the size of Pd particles varies from 8 to $25 \mathrm{~nm}$. Of particles are formed due to the self-assembling nature of palladium tetra chloroacmplox on IRA-410. This self-assembly of the particles also confirms the capping ability of Pd on IRA-410.

Apparatus: Potentiometeric measurements were performed at $25 \pm$ $1^{\circ} \mathrm{C}$ using a Fisher scientific-computer aided $\mathrm{pH} /$ milivoltmeter (Model 450) with a palladium PVC matrix membrane electrodes in conjunction with a double junction $\mathrm{Hg}\left|\mathrm{HgCl}_{2}\right| \mathrm{KCl}$ (satd.) reference electrode (ColeParmer Co., Chicago, Illinois 60648). A Fisher Accumet Model 825 MP $\mathrm{pH}$-meter (accuracy $\pm 0.001 \mathrm{pH}$ ) with a glass $\mathrm{pH}$ electrode (Fisher electrode no. 13-639-90) was used for all $\mathrm{pH}$ measurements). Figure 4: using the $\mathrm{KBr}$ technique was used for infrared measurements. (Figure 3a,b) (Figure 4) (Table 2).

Calibration Curve: Figure 5: These sensors exhibit the maximum working concentration range of $1.0 \times 10^{-7}$ to $1.0 \times 10^{-3} \mathrm{M}$ with a slope of $>16$ mVdecade- 1 of activity (Sensor of Pd (II) ion selective electrode). The PVC-membranes were prepared and aggregation into sensor electrodes using established procedures [20-24]. The prepared membranes contained $1.2 \mathrm{mg}$ ionophore (IRA-410), $0.60 \mathrm{mg}$ lipophilic salt, $60 \mathrm{mg}$ PVC and $10 \mathrm{mg}$ membrane solvent were mixed with $0.5 \mathrm{ml}$ (THF) I mixed together very well and making compact disk with diameter 0.5 $\mathrm{cm}$ and thickness $0.2 \mathrm{~cm}$ and drying. In the glass dish with an diameter of $30 \mathrm{~mm}$ resting on a smooth mould. THF tetrahydrofuran was allowed to evaporate for $48 \mathrm{~h}$ standing at room temperature. Transparent PVC membranes were obtained with a thickness of $0.2 \mathrm{~mm}$. A $11 \mathrm{~mm}$ diameter piece was cut out from the PVC membrane and attached to a PVC tube by means of PVC-THF solution Figure 6: wavelength(nm)

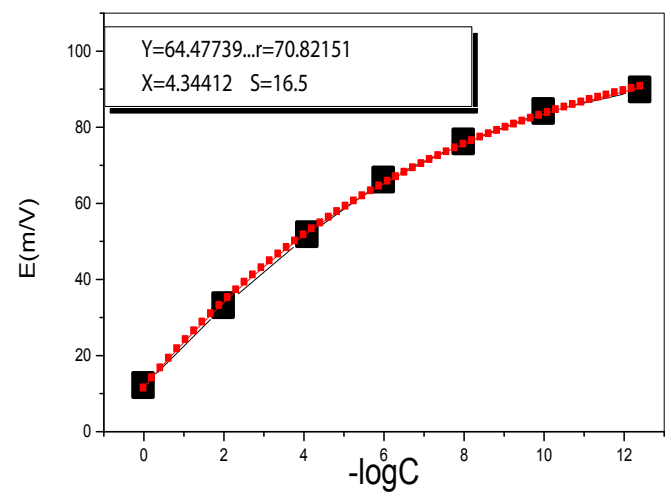

Figure 5: Calibration Curve.

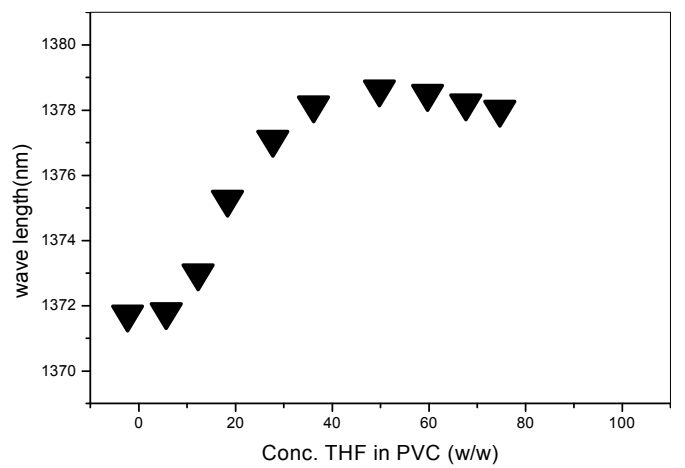

Figure 6: Wavelength (nm) up on solvent (pvc) in aqueous solution 


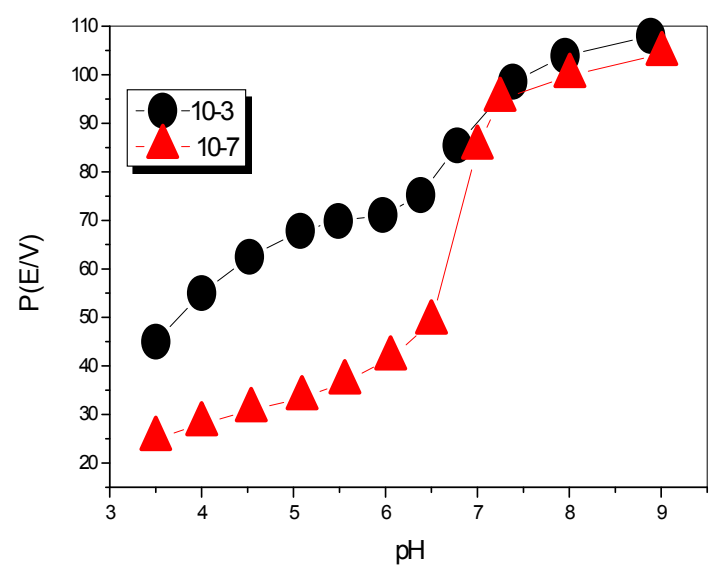

Figure 7: Effect of $\mathrm{pH}$ standard solution $0.1 \mathrm{M}$ of $\mathrm{PdCl} 2$ on IRA-410.

upon solvent(PVC)in aqueous solution as previously described [25]. The PVC tube with the membrane was then incorporated into an $\mathrm{Hg}\left|\mathrm{HgCl}_{2}\right| \mathrm{KCl}$ inner electrode (1.0 mm diameter). The dried tube was filled with internal solution contained $10^{-3} \mathrm{moll}^{-1} \mathrm{pdCl}_{2}$ and $10^{-3} \mathrm{~mol} \mathrm{l}^{-1}$ $\mathrm{KCl}$. Then, the electrode was conditioned for $1 \mathrm{~h}$ in $10^{-3} \mathrm{~mol} \mathrm{l}^{-1} \mathrm{pdCl}_{2}$ solution [26].

Preparation of PVC-membrane: The PVC-membranes were prepared and aggregation into sensor electrodes using established procedures (20-24). The prepared membranes contained $1.2 \mathrm{mg}$ ionophore (IRA-410), $0.60 \mathrm{mg}$ lipophilic salt, $60 \mathrm{mg}$ PVC and $10 \mathrm{mg}$ membrane solvent were mixed with $0.5 \mathrm{ml}$ (THF) I mixed together very well and making compact disk with diameter $0.5 \mathrm{~cm}$ and thickness 0.2 $\mathrm{cm}$ and drying. In the glass dish with a diameter of $30 \mathrm{~mm}$ resting on a smooth mould. THF tetrahydrofuran was allowed to evaporate for $48 \mathrm{~h}$ standing at room temperature. Transparent PVC membranes were obtained with a thickness of $0.2 \mathrm{~mm}$. A $11 \mathrm{~mm}$ diameter piece was cut out from the PVC membrane and attached to a PVC tube by means of PVC-THF solution as previously described (25). The PVC tube with the membrane was then incorporated into an $\mathrm{Hg}\left|\mathrm{HgCl}_{2}\right| \mathrm{KCl}$ inner electrode $(1.0 \mathrm{~mm}$ diameter). The dried tube was filled with internal solution contained $10^{-3} \mathrm{moll}^{-1} \mathrm{pdCl}_{2}$ and $10^{-3} \mathrm{~mol} \mathrm{l}^{-1} \mathrm{KCl}$. Then, the electrode was conditioned for $1 \mathrm{~h}$ in $10^{-3} \mathrm{~mol} \mathrm{l}^{-1} \mathrm{pdCl}_{2}$ solution [26].

Potential measurement: All potential measurements were performed at $25 \pm 1^{\circ} \mathrm{C}$ using a Fisher scientific-computer aided $\mathrm{pH} /$ milivoltmeter (Model 450). The electrochemical system for this electrode can. The performance of the electrode was investigated by measuring its potential in palladium chloride solutions prepared in the concentration range $\left(10^{-1}\right.$ to $\left.10^{-7}\right) \mathrm{mol} \mathrm{l}^{-1}$ by gradual dilution of stock standard solution $0.1 \mathrm{~mol} \mathrm{l}^{-1}$ of $\mathrm{pdCl}_{2}$, with triply distilled water. The potentiometric selectivity coefficients $(\log \mathrm{K}$ Pot $\mathrm{Pd}, \mathrm{B})$ were measured using the separation solution method (SSM) and the mixed solution method (MSM) [27,28]. Dependence of $\mathrm{pH}$ on electrode response was examined (Figure 7): Adjusting the $\mathrm{pH}$ of the measured standard solution with $1 \times 10^{-3} \mathrm{~mol}^{-1}$ hydrochloric acid or sodium hydroxide solutions (Figures 6 and 7).

Underwent response Sensors palladium according the equation Nernstian with selectivity similar and the knowledge that the sensors palladium prepare traditional because we prepare palladium disc, and put the bottom of reference electrode .The electrode signal feels palladium in another solutions whether the sample solution sea water or others and, of course, used plastic films made of PVC, which showed long-term response to senstivity this led to the use of sensors for a long period of more than 6 months and under the continued use of this investigation.

\section{Results and discussion}

\section{Dynamic response time}

Dynamic response time of the Pd (II) sensor: The determination of palladium (II) by potentiometric titration based on the formation of a water-insoluble ion pairs of $\mathrm{PdX} 4^{2-}$ and $\mathrm{PdX}^{3-}$ complexes $\left(\mathrm{X}=\mathrm{Cl}^{-}, \mathrm{Br}^{-}\right.$, $\left.\mathrm{I}^{-}, \mathrm{CN}^{-}, \mathrm{SCN}^{-}\right)[29]$ with a cationic titrant such as alkyl ammonium [3032], alkylphosphonium [33-35] and crystal violet [36] were published. An important requirement for preparation of an ion selective sensor is that membrane electroactive material should have high lipophilicity and strong affinity for a target metal ion and poor affinity to the others.

It is well known that coordination abilities of ligands containing sulfur atom, are very selective to the transition metal ions. However, most of these show some limitations in their working activity range, selectivity, response time, $\mathrm{pH}$ range and lifetime. Thus, the development of reliable sensing ion selective sensors for palladium ion is considerable importance for environment and human health. To improve the analytical selectivity, it is essential to search novel carrier compounds that would interact with palladium ion with high selectivity. Because of the ligand that contain sulphur highly selective for Pd (II), classified as a "soft" Lewis acid. The use of IRA-410 as an ionophore is reported in the construction of a Palladium (II)-PVC membrane electrode and their characteristic and properties of selective electrode were studied. The novelty comes from that it can be used in aqueous and solid phases. The washing was used by elution of palladium absorbed palladium via reduction of palladium by formic acid. It is used for reducing of palladium producing palladium metal and sensing it in metallic palladium. The reduced palladium can be used as sensor hydrogen.

Time response, when total solution effect of the time according the equation (1)

$$
y(t)=\left\{K t+K\left(t_{0}-T\right)_{\frac{-t}{\tau}}\right\}
$$

Where Kt represent yp $(\mathrm{t}) \ldots \ldots \mathrm{K}\left(\mathrm{t}_{0}-\mathrm{T}\right)_{\mathrm{e}}^{-\mathrm{t} / \mathrm{r}} \mathrm{yH}(\mathrm{t})$

The first term from equation describe the particular solution the end term is homogeneous solution. The dynamic response time of the Pd (II) (ISE)s selective electrode, of the most important factors .study

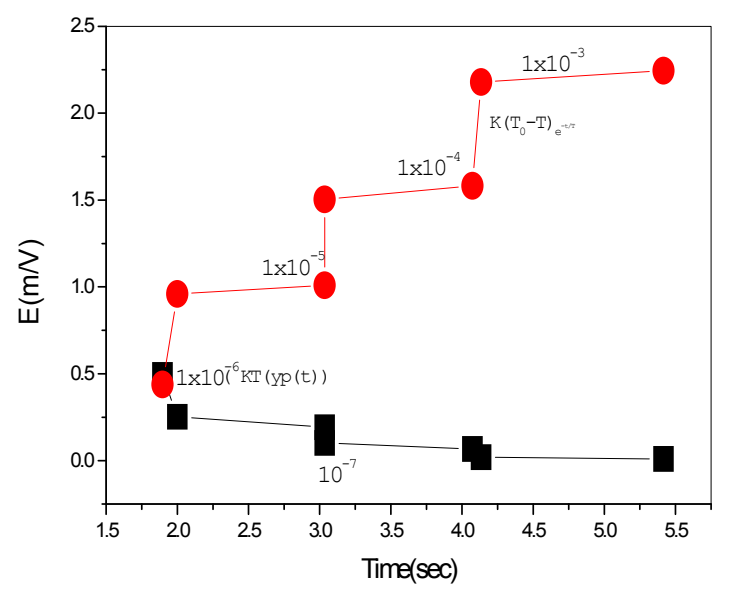

Figure 8: Dynamic Response time of palladium electrode for step changes in the concentration of $\mathrm{pd}(\mathrm{II})$ step $\mathrm{B}\left(1 \times 10^{-7}\right) \mathrm{M}$ in step $\mathrm{F}\left(1 \times 10^{-3}\right) \mathrm{M}$. 


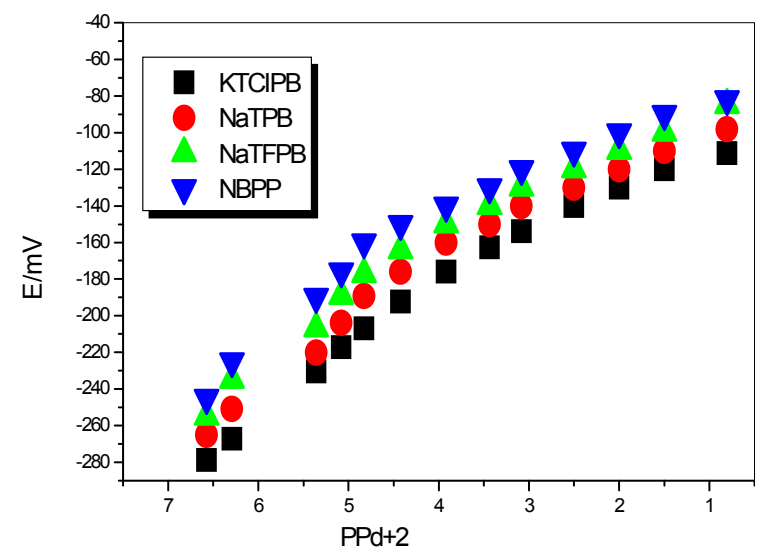

Figure 9: The Potential responses of pd(II) membrane ISEs prepared with different types of potential.

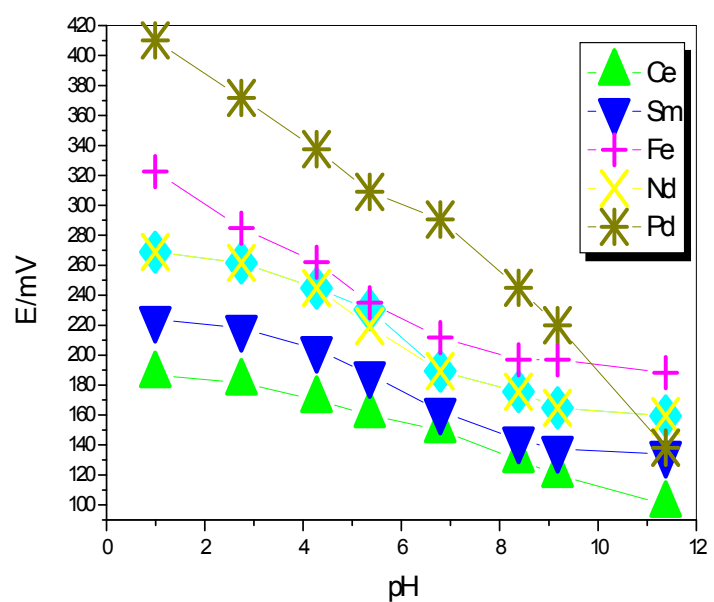

Figure 10: Effect of $\mathrm{pH}$ on the potential responses of $\mathrm{pd}(\mathrm{II})$ ion-selective electrode.

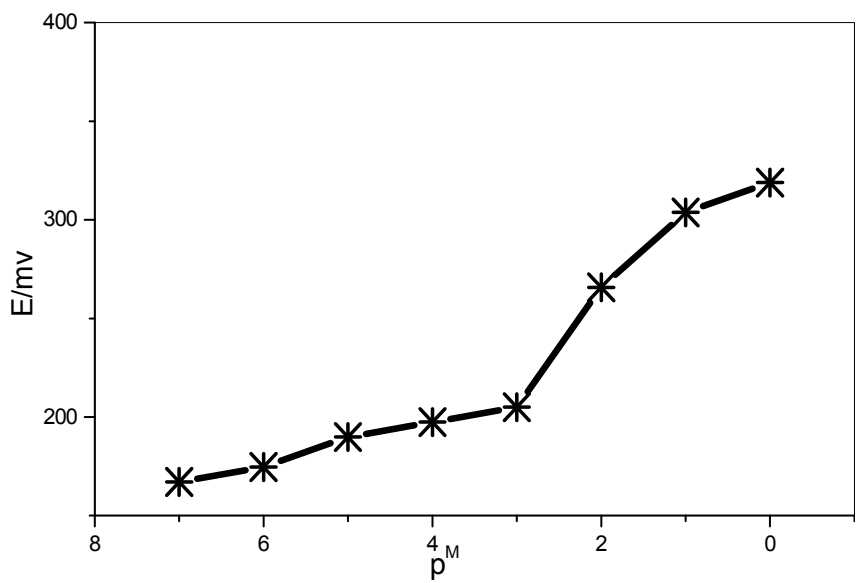

Figure 11: Potential response of various ion-selective membrane based on IRA-410.

the practical for response time of the ion selective electrode recorded by changing of the $\mathrm{Pd}(\mathrm{II})$ concentration in solution from $\left(1.0 \times 10^{-7}\right.$ to $\left.1.0 \times 10^{-3}\right) \mathrm{M}$. The potentials versus time traces are shown in Figure 8 . As can be seen, the whole concentration range of plasticized membrane electrode reaches its equilibrium responses in a very short time $(<1 \mathrm{~s})$

\section{Membrane composition}

Due to some similarities between the functional groups of IRA-410 with those of the previously reported ligating molecules for lanthanide ions, and especially for palladium ion [2-6] as well as its negligible water solubility, we decided to examine the suitability of IRA-410 as potential ionophore in constructing some lanthanide ion-selective electrodes. Our preliminary solution studies revealed that, NBPP forms a quite stable complex with Pd (II) ion, which readily precipitates out from dioxan solution. While the extent of complexation of transition metal ions as well as other lanthanide such as Fe (III), Nd (III) and Sm (III) with IRA-410 was found to be much lower, as was examined by segmented sandwich membrane method [37]. Subsequently, the ligand IRA-410 was tested as an ionophore for the preparation of a variety of ions, mono, di, and trivalent metal ion-selective electrodes. The potential response of various ion-selective electrodes based on the proposed ionophore is shown in Figure 10. As expected, among different cations tested, Pd (II) with the most sensitive response seems to be suitably determined with the PVC membrane based on ligand NBPP. While the response slope of the other ion-selective electrodes are much lower the values expected from Nernstian equation, although in a limited concentration range. The response of membrane electrode depends on some parameters such as plasticizer-PVC ratio, amount of ionophore and additive used since; the nature of plasticizer influences the dielectric constant of the membrane phase both the mobility of ionophore molecules and the state of ligands [38-41]. It was expected to play a key role in the determining the ion-selective electrode characteristics. Polar plasticizers lead to the lowering of the membrane resistance as compared with polar plasticizers, which contain other functional groups with potential coordination sites which might [42] compete with carrier Thus, several solvents such as THBE, EHBS, DOP, o-NDPE, o-NPPE, and were tested (Figures 9-11). In fact, the Pd (II) ion-selective electrode based on IRA-410 better than the other examined mediators. It has a good Nernstian slope of $19.5 \pm 0.2 \mathrm{mV}$ decade- 1 over a wide of concentration range from $10^{-1}$ to $2.5 \times 10^{-6} \mathrm{~mol}$ $\mathrm{l}^{-1}$, with detection limit of $1.6 \times 10^{-6} \mathrm{~mol} \mathrm{l}^{-1}$. On the other hand, THBE, EHBS, DOP, o-NDPE and o-NPPE solvents give non-Nernstian slopes of $12.5,28,14.6,9.8$, and 12.4 , respectively.

Response of different anions: In preliminary experiments, various PVC-membrane ion-selective electrodes with the synthesized ion pair were prepared and tested for different anions. The potential response of the electrode for different anions is shown in Figure 9: The results exhibited significantly high selectivity to palladium ion over other anions. Hence, ion pair was selected as a carrier for preparation of palladium selective electrode.

\section{Preparation of sandwich membrane}

A potentiometric method to determine ionophore complex formation constants in solvent polymeric membrane phases, it requires membrane potential measurements on two-layer sandwich membranes, where only one side contains the ionophore. If both membrane segments have the same ionic strength, it is convenient to assume that the activity coefficients for the complexed and uncomplexed ions are approximately equal. In that case, they can be omitted and the complex constant is related to the potential .This relationship allows for the convenient determination of formation constants of ionophore complexes within the membrane phase on the basis of transient membrane potential 


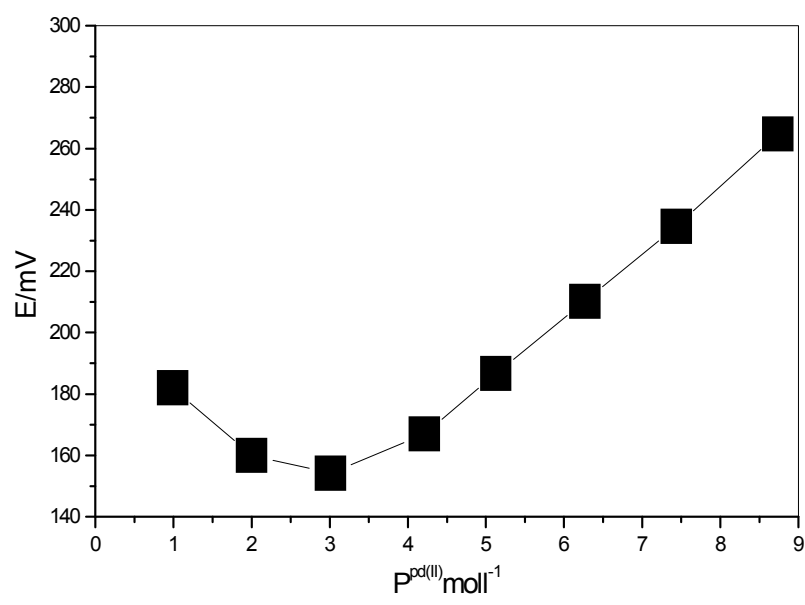

Figure 12: Effect of lipophilic anions on potential responses of $\operatorname{pd}($ II) selective electrode based on IRA-410 ionophore for different concentrations.

\begin{tabular}{|c|c|}
\hline Interfering ions & $\log K={ }_{p(I I)}^{M P M}$ \\
\hline $\mathrm{Ce}^{3+}$ & -3.00 \\
\hline $\mathrm{Sm}^{3+}$ & -2.89 \\
\hline $\mathrm{Fe}^{3+}$ & -3.02 \\
\hline $\mathrm{Nd}^{3+}$ & -3.10 \\
\hline
\end{tabular}

Table 3: Comparison of the selectivity coefficients of different pd(II) electrodes.

measurements on two-layer sandwich membranes can be if ion pairing neglected. Ion-selective electrode membranes were cast by mixing the recorded membrane components to give a total cocktail mass of 181.8 $\mathrm{mg}$ in $2 \mathrm{ml}$ of THF. The solvent THF allowed evaporating overnight. A series of disks were cut with a cork borer from the parent membrane. These disks were conditioned overnight in each of metal chloride 0.01 $\mathrm{M}$ salt solutions shown in Figure 10 of Ce (III), Sm (III), Fe (III) and Nd (III). All membrane electrode potential measurements were performed at laboratory ambient temperature in unstirred salt solution (identical to the conditioning and inner filling solution) versus $\mathrm{Ag} / \mathrm{AgCl}$ reference electrode. Sandwich membrane was made by pressing two individual membranes (ordinary one without ionophore and one with the same components and additional ionophore) together immediately after blotting them individually, dry with tissue paper. The combined segmented membrane was then rapidly mounted into the electrode body and immediately measured. The time required from making the membrane sandwich contact until final membrane potential measurement was less than $1 \mathrm{~min}$.

\section{Sample preparation}

Determination of palladium sample by Potentiometeric titrations: THF $(15.0 \mathrm{~mL})$ was placed in the titration vessel and the required volume of the investigated acid and two drops of the indicator solution were added. The indicator electrode, either $\mathrm{H} 2 / \mathrm{Pd}$ or glass electrode and a SCE as the reference one were immersed in the investigated solution and connected to a $\mathrm{pH}$-meter. The solution was then titrated with standard solution of (potassium hydroxide or sodium methylate) and the potential was read after each addition of titrant. The test solution was stirred magnetically under a continuous stream of dry nitrogen (Figures 9-11).

\section{The optimization of permselectivity of membrane sensors}

The optimization of permselectivity of membrane sensors is known to be highly dependent on the incorporation of addition a membrane components. In fact it has been demonstrated that, the presence of lipophilic negatively charged additives improves the potentiometric behavior of certain cation-selective electrodes by reducing the ohmic resistance and improving the response behavior and selectivity $[43,44]$. Some of the lipophilic ions such as, potassium tetrakis (4-chlorophenyl) borate (KTClPB), sodium tetra phenyl borate (NaTPB), sodium tetrakis (1-imidazolyl borate) (NaIB) and sodium tetrakis (4-fluorophenyl) borate dehydrate (NaTFPB), were tested (Figure 12). It has been found that, the suitable lipophilic additive which improves the sensitivity of Pd (II) electrode was KTClPB with a good Nernstian slope of $19.5 \pm$ 0.2 mVdecade-1. While the other lipophilic ions have slopes of 21, 13.6 and 9 , respectively (Figure 11). Shown that the potential response of various ion-selective membranes based on IRA-410. The amount of ionophore has effect on the electrode sensitivity. So that, amounts of NBPP carrier $(0.8,1.2$ and $1.6 \mathrm{mg})$ were examined. The results indicate that, the membrane containing $1.20 \mathrm{mg}$ NBPP ionophore exhibits a good Nernstian slope of $19.5 \pm 0.2 \mathrm{mV}$ decade- 1 and high selectivity of Pd (II) ion.

\section{Effect of internal solution, response time and $\mathrm{pH}$}

The working of membrane electrode in relation to variation of reference solutions was investigated. It was found that, the variation of the concentration of the internal solution $\left(10^{-1}\right.$ to $10^{-4} \mathrm{~mol}^{-1}$ of $\mathrm{KCl}$ solution) causes significant effect on corresponding potential response. However a solution of $10^{-3} \mathrm{moll}^{-1} \mathrm{KCl}$ mixed with $10^{-3} \mathrm{~mol} \mathrm{l}^{-1}\left[\mathrm{pdCl}_{4}\right]^{-4}$ would be used as a suitable internal solution, it had a good slope $19.5 \pm$ $0.2 \mathrm{mV}$ decade-1. The detection limit, taken at the point of intersection of the extrapolated linear segment of the calibration curve, was $1.6 \times 10^{-6}$ moll $^{-1}$. The static response time of the membrane electrode thus obtained was $<10 \mathrm{~s}$. The sensing behavior of the electrode remained unchanged when the potential recorded from low to high concentrations or vice versa. The life time of the present electrode was at least 3 months. During this time, the detection limit of the electrode remained almost constant and the slope of the response decrease from $16.5 \pm 0.2$ to $16.1 \pm 0.15 \mathrm{mV}$ decade $^{-1}$. After this time the electrochemical behavior of the electrode gradually deteriorates. The effect of $\mathrm{pH}$ on the response of the electrode was studied over the $\mathrm{pH}$ range from 1 to 11 at different concentrations $\left(10^{-2}\right.$ to $\left.10^{-5} \mathrm{moll}^{-1}\right)$ of $\mathrm{Pd}$ (II) solution. The $\mathrm{pH}$ of solutions was adjusted with either $\mathrm{HCl}$ or $\mathrm{NaOH}$ solutions. Potential remains constant at $\mathrm{pH}$ range from 4 to 8 (Figure 12). The increase of potential below $\mathrm{pH} \sim 4$ may be ascribed to interference by $\mathrm{H}+$ ion and the decrease of potential above $\mathrm{pH}=8$ may be due to formation of some hydroxyl complex of the $\mathrm{pd}(\mathrm{II})$ ions in solution from hydrolysis of palladium chloride. The performance of the electrode was assessed in partially non-aqueous media using ethanol-water mixture; it is observed that the electrode functions well in presence of up to $10 \%(\mathrm{v} / \mathrm{v})$ non-aqueous (alcoholic) content. Higher alcoholic content disturbs the functioning of system (Figure 12).

\section{Electrode selectivity}

The influence of interfering ions on the response behavior of ion-selective membrane electrode is usually described in terms of selectivity coefficient log Potpalladium B. The potentiometric selectivity coefficients $\log$ Pot palladium B of palladium electrode were evaluated by (SSM) and (MSM) $(27,30,31)$. The resulting values of the selectivity coefficients are summarized in Table 3 . It is evident from the selectivity coefficients data, that the sensor exhibits a high performance for Pd 
Citation: Kassem AT, El Said N, Aly HF (2014) New lon Selective Sensitive Electrode of Pd (II) as Multisensor Based on IRA-410 via Low Cost Oxidation Reduction Process. J Membra Sci Technol 4: 127. doi:10.4172/2155-9589.1000127

Page 6 of 7

(II) ion compared with alkali, alkaline-earth, transition and heavy metal ions. Comparison of the main analytical features of some the previously described pd(II) ion-selective [18-22] electrodes) with the proposed Pd (II) electrode revealed that, the present electrode exhibited a better selectivity, especially in the presence of $\mathrm{Hg}$ (II) and Fe (III). This participation of these functional groups in the binding with $\mathrm{pd}(\mathrm{II})$ ions. Elemental analysis of NBPP and its Pd (II) complex was examined and showed that, the formation of NBBP-pd(II) complex for a membrane segment may form with the complex stoichiometry $\mathrm{n}=1$. Membrane potential values emf for the examined metal salt solutions of Ce (III), Sm (III), Fe (III) and Nd (III) were deter-mined by subtracting the cell potential for a membrane without ionophore from that of the sandwich membrane. The determined formation constants ( $\log \beta$ ILn) for the examined different complexes were recorded in Table 3. A careful analysis of the data in, reveals that pd(II) has significant cation-binding characteristics. A comparison between the potentiometric behaviors of the proposed electrode with the previously reported ISEs for Pd (II).

\section{Determination of cations in some pharmaceutical samples.}

Samples containing $50 \mathrm{ml}$ of distilled water and stirred for $3 \mathrm{~h}$ in thermostat adjusted to $25 \pm 1^{\circ} \mathrm{C}$ and allowed to stand to 2 that the same temperature before potential measurement. The palladium selective electrode and reference electrode were immersed in the precipitate solution. The concentration of soluble pd(II) ions was measured and Solubility product was calculated for cerium oxalate was $2.2 \times 10^{-26}$ while reference was $3.2 \times 10^{-26}$ and for cerium phosphate was $2.3 \times 10^{-23}$ while reference was $1 \times 10^{-23}$ with small deviation of reference (Table 3 ).

\section{Determination of palladium in some water and radioactive waste samples}

As discussed before palladium cation can be determined in water and radioactive waste samples

\section{Reaction mechanism}

The formation of $\left[\mathrm{PdCl}_{4}\right]^{-2}$ species are suggested to be bounded to the resin. This concept is supported by the considerable stability of the formed palladium tetrachloro complex $\left(\mathrm{PdClO}_{4}=15\right)$. The complex formation of palladium tetrachloro complexes explains the fast loading of palladium on the resin phase as a brown zone which may be formed as a tetrachloro complex. It, also, explains the difficulty of elution which is attributed to the stability of $\left[\mathrm{PdCl}_{4}\right]_{2}$ complex. Therefore, the separation of the complexed palladium from the solid phase can be carried out via reduction using the weak complexing agent; formic acid [1]. To explain the reduction steps of palladium chloride by formic acid, the reduction using ethylene was consulted [2] in comparison to the following reduction reaction case. In this respect the following steps are suggested [1]. Sepaon Mechanism: The formation of a complex for a metal ion $\mathrm{M}^{+}$with the following steps is also suggested;

The following steps are also suggested

a. $\mathrm{HCOOH}+\mathrm{R}\left[\mathrm{PdCl}_{4}\right]^{2} \stackrel{K_{1}}{\longrightarrow} \mathrm{R}\left[\mathrm{PdCl}_{3}(\mathrm{H} 000 \mathrm{H})\right]+\mathrm{C} 1$

b- $\mathrm{R}\left[\mathrm{PdCl}_{3}(\mathrm{H} 000 \mathrm{H})\right]+\mathrm{H}_{2} \mathrm{O} \stackrel{K_{2}}{\longrightarrow} \mathrm{R}\left(\mathrm{Pd}(\mathrm{HCOOH})\left(\mathrm{OH}_{2}\right) \mathrm{Cl}_{2}\right)$ $+\mathrm{C} 1$

c- $\mathrm{R}\left(\mathrm{Pd}(\mathrm{HCOOH})\left(\mathrm{OH}_{2}\right) \mathrm{Cl}_{2}\right) \stackrel{\sim K_{3}}{\longrightarrow} \mathrm{R}[\mathrm{Pd}(\mathrm{HCOOH})(\mathrm{OH})$ $\left.\mathrm{Cl}_{2}\right]+\mathrm{H}^{+}$

d- Step (c) indicates that the rate of the reduction process is reversibly proportional to the $\mathrm{H}^{+}$concentration which explains its increase by decreasing the formic acid concentration.
The complexed species formed in step (c) are suggested to go via possible rearrangements through an addition of an $\mathrm{OH}$ group [14]; as in $(\mathrm{d})$ :

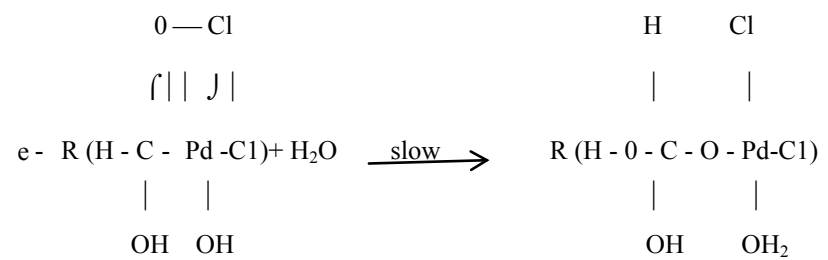

Step (d) is suggested to be the rate determining step where the addition of the hydroxide ion to the coordinated formic acid occurs. This step is followed by a proposed fast reaction as in (e):

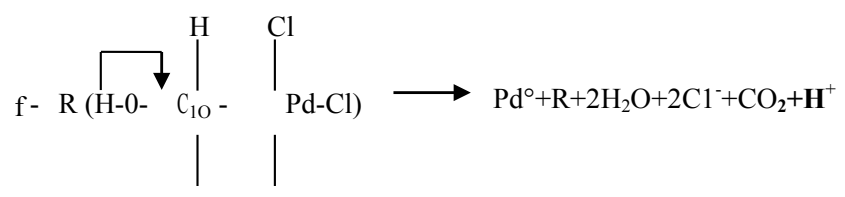

$\mathrm{OH} \quad \mathrm{OH}_{2}$

\section{Conclusion}

New ion selective sensitive electrode of Pd (II) as multisensor based on IRA-410 via low Cost oxidation reduction process as membrane disc sensor from. It can be used as sensor in $\mathrm{HCl}$ solution as $\left(\mathrm{PdCl}_{4}\right)^{2}$ in, Pdo sorbed on solid phase IRA-410 and eluted as $\mathrm{Pd}\left(\mathrm{NO}_{3}\right)^{2}$ in nitrate medium. This electrode has a wide linear dynamic range $\mathrm{d}$ low detection limit of $1.6 \times 10^{-6} \mathrm{~mol} \mathrm{l}^{-1}$. It has a fast response time $(<1 \mathrm{~s})$ and good selectivity with respect to different metal ions in $\mathrm{pH}$ range from (1.0-9.0). It can be used for about 10 months with complex with Pd (II) was calculated by using segmented sandwich membrane method. The proposed electrode has been used successfully as an indicator electrode in potentiometric determination in aqueous nitrate and /or chloride media.

\section{References}

1. El-Said N, Mekhail A, Khalifa SM, Aly HF (1996) Selective separation of palladium from simulated intermediate radioactive waste nitrate by IRA-410 and IRA-900 anion exchanger. J Radioanalytical and Nuclear Chemistry 208 243-255.

2. El-Said N, Siliman AM, El-Sherif E, Borai EH (2002) Separation of palladium from simulated intermediate radioactive waste/chloroacetic acid/nitrate medium by IRA-410 and IRA-900 anion exchangers. J Radioanalytical and Nuclear Chemistry 251: 285-292

3. El-Said N, Mekhael AS, Khalifa SM, Aly HF (1995) Separation of strontium from simulated waste in K2SO4/Nitrate medium containing $\mathrm{Sr} 2+$, Eu3+, Ce3+ $\mathrm{Pd} 2+, \mathrm{Rh} 3+, \mathrm{Ru} 3+, \mathrm{UO} 22+, \mathrm{Fe} 3+, \mathrm{Cr} 3+, \mathrm{Ni2}+, \mathrm{Al} 3+, \mathrm{Ca} 2+$ and $\mathrm{Cs}+$, by strongly basic anion exchanger. J Radioanalytical and Nuclear Chemistry 208: 257-270.

4. Amini MK, Shahrokhian S, Tangestaninejad S (1999) Thiocyanate-selective electrodes based on nickel and iron phthalocyanines. J Anal Chim Acta 402.

5. Shamsipur M (2001) A dinuclear zinc complex with (E)-4-dimethylamino-N'-(2hydroxybenzylidene)benzohydrazide. J Anal Chem 73

6. Ganjali M, Poursaberi T (2001) Using PVC ion-selective electrodes for the potentiometric flow injection analysis. J Anal Chem 370

7. Khan AA, Inamuddin (2004) Applications of $\mathrm{Hg}$ (II) sensitive polyaniline $\mathrm{Sn}(\mathrm{IV})$ phosphate composite cation-exchange material in determination of $\mathrm{Hg} 2+$ from aqueous solutions and in making ion-selective membrane electrode. Sensors and Actuators B: Chemical 120: 10-18.

8. Khan AA (2003) A Sensitive Cigarette Smoke Sensor - International Frequency. Sensors and Actuators B 120 . 
Citation: Kassem AT, El Said N, Aly HF (2014) New lon Selective Sensitive Electrode of Pd (II) as Multisensor Based on IRA-410 via Low Cost Oxidation Reduction Process. J Membra Sci Technol 4: 127. doi:10.4172/2155-9589.1000127

9. Ahmad M, Hashim N, Ghani SA (2011) Cobalt(II) selective membrane electrode based on palladium(II) dichloro acetylthiophene fenchone azine. J Talanta 87.

10. Dhiman SB, LaVerne JA (2013) Radiolysis of simple quaternary ammonium salt components of Amberlite resin. J Nuclear Materials 436: 8-13.

11. Wren JC (1983) Literature study of volatile radioiodine release from ionexchange resins during transportation. J Kysela R Pejsa Radiat Phys Chem 22.

12. Devi PSR, Joshi S, Verma R, Lali AM, Gantayet LM (2010) Radiation-induced decomposition of anion exchange resins. J Radiat Phys Chem 79.

13. Iwai Y, Yamanishi T, Hiroki A, Tamada M (2009) Procurement Preparation of ITER Key Components by JADA. J Fusion Sci Tech 56

14. Pillay KKS (1986) Effects of lonizing Radiation on Modern Ion Exchange Materials. J Radio Nucl Chem I 102.

15. Pandey PC, Prakash R (1998) Characterization of Electropolymerized Polyindole Application in the Construction of a Solid State, Ion Selective Electrode. J Electrochemical Society 12

16. Amed MT, Clay PG, Hall GR (1966) Radiation-induced decomposition of ionexchange resins. Part II. The mechanism of the deamination of anion-exchange resins. J Chem Soc B 102.

17. Qin Y, Peper S, Bakke E (2002) Plasticizer-Free Polymer Membrane Ion-Selective Electrodes Containing a Methacrylic Copolymer Matrix. J Electroanalysis 14

18. Hall GR, Streat M (1963) The solubility of silver chloride in methanol and water mixtures. J Chem Soc 114.

19. Baidak M, Badali JA, LaVerne (2011) Radiation Chemical Effects with Heavy lons. J Chem Sci 115.

20. Moody GJ, Oke RB, Thomas JDR (1970) A calcium-sensitive electrode based on a liquid ion exchanger in a poly(vinyl chloride) matrix. J Analyst 95.

21. Cragge GJ, Moody, Thomas JDR (1974) Experiments with the pvc matrix membrane calcium ion-selective electrode. J Chem Educ 51

22. Ma TS, Hassan SSM (1982) Organic Analysis Using lon-selective Electrodes: Methods 1. Academic Press, London, UK.

23. Saleh MB, Abdel Gaber AA (2001) Novel Zinc lon-Selective Membrane Electrode Based on Sulipride Drug. J Electroanalysis 13.

24. Sombatsompop N (2004) Structural changes of PVC in PVC/LDPE melt-blends: Effects of LDPE content and number of extrusions. J Polymer Engineering and Science 44.

25. El-Nemmaa EM, Badawi NM, Hassan SSM (2009) Cobalt phthalocyanine as a novel molecular recognition reagent for batch and flow injection potentiometric and spectrophotometric determination of anionic Surfactants. J Talanta 78

26. Nataliya M (2013) Nanocrystalline $\mathrm{ZnO}(\mathrm{Ga})$ : Paramagnetic centers, surface acidity and gas sensor properties. J Sensors Actuators B: Chemical 186.

27. Koteswara (2014) Construction and performance characteristics of polymeric membrane electrode and coated graphite electrode for the selective determination of $\mathrm{Fe} 3+$ ion $\mathrm{J}$ : Materials Science and Engineering 36.
28. Mi Y, Bakker E (1999) lon-Selective Electrode Characteristics. J Anal Chem 71

29. Vytras K (1985) Stabilizing Potential of Solid-Contact Sensors Selective towards Surface-Active Substances. J lon-Sel Electrode Rev 7.

30. Scibone G, Mantella L, Danesi PR (1970) Liquid anion membrane electrodes sensitive to metal cation concentration. J Anal Chem 42.

31. Yu M, Sednew EM, Rakhmanko GL, Starobinets (1985) Potentiometric titration of palladium(II) halide complex. J Anal Khim 40.

32. Vytrs K, Kalous J, Simickova B, Cerna J, Silena I (1988) Potentiometric titration of palladium(II) halide complex anions based on ion-pair formation. J Anal Chim 357.

33. Stvlgiene S, Tautkus R, Kazlauska OM, Petrukhin Z (1990) Electroanalysis: From Laboratory to Field Versions Lab 56.

34. Kazluskas R, Jankauskas V, Petrukhin (1986) Theory and applications of ionselective electrodes: Part 7. J lonnyi Obmen lonometriya 5.

35. Badr I, Meyerhoff M, Hassan S (1995) Membrane sensors for batch and flow injection potentiometric. J Anal Chem 67.

36. Vasilev VA, Gurev IA, Zavod (1989) Effect of Palladium on Thermal Degradation of Fiban K-1 Lab. 55

37. Bakker E, Buhlmann P, Pretsch E (1997) Carrier-Based Ion-Selective Electrodes and Bulk Optodes. 1. General Characteristics. J Chem Rev 97

38. FakhariAR, Shamsipur M (1997) Development of a highly selective voltammetric sensor for nanomolar detection of mercury ions using glassy carbon electrode modified with a novel ion imprinted polymeric nanobeads and multi-wall carbon nanotube. J Anal Chem 99

39. Wongsan W (2013) Bifunctional polymeric membrane ion selective electrodes using phenylboronic acid as a precursor of anionic sites and fluoride as an effector: A potentiometric sensor for sodium ion and an impedimetric sensor for fluoride ion. J Electrochimica Acta 111.

40. Kim YJ, Kim J, Kim YS, Lee JK (2013) Erratum to "TiO2-poly(4-vinylphenol) nanocomposite dielectrics for organic thin film transistors" [Org. Electron. 14 (2013) 3406-3414]. Organic Electrons 15: 640.

41. Khan Kabir-ud-din AA, Beg MA (2014) Potentiometric estimation of potassium hydroxotetracyanotungstate(IV) and determination of standard potential. J Electroanalytical Chemistry 20: 239-244.

42. Eugster R (1991) Study of the influence of polymeric membrane composition on the sensitivity of acoustic wave sensors for metal analysis. J Anal Chem 63

43. Stoica Al (2014) Heavy metals determination from food and pharmaceutical samples Development of sensors, biosensors and immunosensors. J Electrochimica Acta 113.

44. Bakker E (2014) Enhancing ion-selective polymeric membrane electrodes by instrumental control. J Trends in Analytical Chemistry 53. 